\title{
Determination of the molecular structure of amorphous $\mathrm{Mg}\left(\mathrm{B}_{3} \mathrm{H}_{8}\right)_{2}(\mathrm{THF})_{2}$ through
}

infrared spectroscopic and computational studies

O. Palumbo ${ }^{1}$, P. Nguyen, ${ }^{2}$ C. M. Jensen,${ }^{2}$ A. Paolone ${ }^{1, *}$

${ }^{1}$ CNR-ISC, U.O.S. La Sapienza, Piazzale A. Moro 5, 00185 Roma, Italy

${ }^{2}$ Department of Chemistry, University of Hawaii, 2545 McCarthy Mall, Honolulu, Hawaii 96822, United States

\section{ABSTRACT}

The infrared absorption spectrum of amorphous $\mathrm{Mg}\left(\mathrm{B}_{3} \mathrm{H}_{8}\right)_{2}(\mathrm{THF})_{2}$ was measured in the mid-infrared region between 600 and $3300 \mathrm{~cm}^{-1}$. In the frequency range corresponding to $\mathrm{B}-\mathrm{H}$ stretching vibrations, the observation of absorptions due to the movements of $\mathrm{Mg}-\mathrm{H}-\mathrm{B}$ bridging hydrides provides evidence of direct bond between octahydrotriborate ions and magnesium. Starting from this configuration, DFT and ab-initio calculations at the MP2, B3LYP and B97D level were utilized in order to find the lowest energy geometry of the $\mathrm{Mg}\left(\mathrm{B}_{3} \mathrm{H}_{8}\right)_{2}(\mathrm{THF})_{2}$ complex. The results of all the computational studies indicate that the interaction of $\mathrm{Mg}$ with the $\left[\mathrm{B}_{3} \mathrm{H}_{8}\right]^{-}$ions entails two $\mathrm{B}-\mathrm{Mg}$ and two $\mathrm{B}-\mathrm{H}-\mathrm{Mg}$ bonds. The calculated infrared absorptions closely reproduce the experimental spectrum. Moreover, calculations provide evidence of the stabilization of the THF solvate of $\mathrm{Mg}\left(\mathrm{B}_{3} \mathrm{H}_{8}\right)_{2}$ and indicate that the THF complex has a greater stabilization energy than dialkyl ethers complexes by $\sim 25 \mathrm{~kJ} / \mathrm{mol}$.

KEYWORDS

* Corresponding author: Annalisa Paolone, CNR-ISC, Piazzale A. Moro 5, I-00185 Rome, Italy E-mail: Annalisa.Paolone@roma1.infn.it Fax: +39-06-4969 4323 Tel.: +39-06-4991 4400 
Infrared spectroscopy; DTF calculations; ab-initio calculations; structure; amorphous; solvation energy

\section{INTRODUCTION}

$\mathrm{Mg}\left(\mathrm{BH}_{4}\right)_{2}$ has attracted recent interest due to its high hydrogen content ( 14.9 wt\%) and the measured low enthalpy of dehydrogenation $\left(-57 \pm 5 \mathrm{~kJ} / \mathrm{mol} \mathrm{H}_{2}\right)$.[1-3] Experimentally, the direct hydrogenation from $\mathrm{MgB}_{2}$ requires extreme conditions $\left(\mathrm{T}>400^{\circ} \mathrm{C}, \mathrm{p} \sim 900\right.$ bar).[4] However, reversible dehydrogenation has been demonstrated to occur under milder conditions ( $T \sim 250^{\circ} \mathrm{C}, \mathrm{p} \sim 120$ bar) [5] according to following the equation:

$$
3 M g\left(B H_{4}\right)_{2} \Leftrightarrow M g\left(B_{3} H_{8}\right)_{2}+2 M g H_{2}+2 H_{2}
$$

which corresponds to a reversible capacity of $\sim 2.5 \%$. More recently, it has been reported that even milder conditions ( $50 \mathrm{bar}_{2}, 200^{\circ} \mathrm{C}, 2 \mathrm{~h}$ ) can be used for hydrogenation of a 1:2 molar mixture of $\mathrm{Mg}\left(\mathrm{B}_{3} \mathrm{H}_{8}\right)_{2}(\mathrm{THF})_{2}$ (where $\mathrm{THF}=$ tetrahydrofuran) and $\mathrm{MgH}_{2}$ to $\mathrm{Mg}\left(\mathrm{BH}_{4}\right)_{2 \cdot[6]}$

To the best of our knowledge, there were no reports of the synthesis of $\mathrm{Mg}\left(\mathrm{B}_{3} \mathrm{H}_{8}\right)_{2}(\mathrm{THF})_{2}$ prior to the study of Ref. 6 and the complex has not been structurally characterized. However, the amorphous nature of this complex prevents the use of diffraction for the determination of its structure. The NMR measurements clearly indicate the presence of the octahydrotriborate $\left[\mathrm{B}_{3} \mathrm{H}_{8}\right]^{-}$ion in the sample as well as the presence of a THF adduct.[6] However, more information about the interaction of the THF molecules and the $\left[\mathrm{B}_{3} \mathrm{H}_{8}\right]^{-}$ions with $\mathrm{Mg}$ would greatly enhance the understanding of this compound and provide valuable insight into the mechanism of its reversible hydrogenation. These structural details can be revealed by a combination of infrared spectroscopy and DFT calculations. 
The infrared spectra of molecules containing $\mathrm{BH}$ bonds has been extensively studied and a systematic attribution of $\mathrm{BH}$ stretching bands to different molecular structures has been reported.[7] In particular, Kim et al. [8] pointed out that magnesium and $\left[\mathrm{B}_{3} \mathrm{H}_{8}\right]^{-}$compounds containing ether solvates can have a ionic or a non-ionic character. In the first case, $\mathrm{Mg}$ is coordinated only to the ether molecules (for example, in $\mathrm{Mg}(\mathrm{THF})_{6}\left(\mathrm{~B}_{3} \mathrm{H}_{8}\right)_{2}$ and in $\left.\mathrm{Mg}(\text { diglyme })_{2}\left(\mathrm{~B}_{3} \mathrm{H}_{8}\right)_{2}\right)$ and in the infrared spectrum one observes only the absorption bands due to bridging B-H-B (around $2100 \mathrm{~cm}^{-1}$ ) and to terminal B-H (above $2400 \mathrm{~cm}^{-1}$ ) stretching. On the other hand, $\mathrm{Mg}\left(\mathrm{B}_{3} \mathrm{H}_{8}\right)_{2}, \mathrm{Mg}\left(\mathrm{B}_{3} \mathrm{H}_{8}\right)_{2}\left(\mathrm{Et}_{2} \mathrm{O}\right)_{2}$ and $\mathrm{Mg}\left(\mathrm{B}_{3} \mathrm{H}_{8}\right)_{2}\left(\mathrm{Me}_{2} \mathrm{O}\right)_{2}$ are molecular species with a direct bond of $\mathrm{Mg}$ to the octahydrotriborate ions and they display an additional stretching band around $2300 \mathrm{~cm}^{-1}$ due to the bridging $\mathrm{Mg}-\mathrm{H}-\mathrm{B}$ movements.[8] Moreover, $\left[\mathrm{B}_{3} \mathrm{H}_{8}\right]^{-}$ions can be coordinated to an atom, $\mathrm{M}$, by means of one or more $\mathrm{B}-\mathrm{M}$ chemical bonds, with additional $\mathrm{H}-\mathrm{M}$ bonds. For example, in $\mathrm{Mg}\left(\mathrm{B}_{3} \mathrm{H}_{8}\right)_{2}\left(\mathrm{Et}_{2} \mathrm{O}\right)_{2}$ and $\mathrm{Mg}\left(\mathrm{B}_{3} \mathrm{H}_{8}\right)_{2}\left(\mathrm{Me}_{2} \mathrm{O}\right)_{2}$ there are two B-Mg and two $\mathrm{H}-\mathrm{Mg}$ bonds for each octahydrotriborate ion. [8] However, in $\mathrm{Ag}\left(\mathrm{CNB}_{3} \mathrm{H}_{7}\right)_{2}{ }^{-}$there is one $\mathrm{B}-\mathrm{N}$ and two $\mathrm{H}-\mathrm{N}$ bonds.[9] In the crystal structure of $\mathrm{NaB}_{3} \mathrm{H}_{8}$, each $\mathrm{Na}$ is surrounded by four octahydrotriborate anions: for two of them, $\mathrm{Na}$ is closer to two $\mathrm{B}$ atoms, while for the other $\left[\mathrm{B}_{3} \mathrm{H}_{8}\right]^{-}$ions, $\mathrm{Na}$ is closer to a single B. $[9,10]$ Finally, the low temperature solid phase of $(\mathrm{CO}){ }_{3} \mathrm{MnB}_{3} \mathrm{H}_{8}$ contains three $\mathrm{Mn}-\mathrm{H}-\mathrm{B}$ bridging hydrides, one bridge bond for each boron atom.[11]

Serrar et al. showed that ab-initio calculations at the MP2 level of theory and of density functional theory methods at the B3LYP level can be applied to the study of the structure of the isolated $\left[\mathrm{B}_{3} \mathrm{H}_{8}\right]^{-}$ion and the $\mathrm{ClCuB}_{3} \mathrm{~B}_{8}$ complex.[12, 13] These authors found that in the complex the most stable structure is that in which two boron atoms are bound to the $\mathrm{Cu}$ atom via two $\mathrm{B}-\mathrm{H}-\mathrm{Cu}$ hydrogen bonds (one bridge bond for each $\mathrm{B}$ atom). Guided by these previous studies, we have utilized a combination of infrared spectroscopy measurements, ab-initio and DFT calculations in order to determine the most stable 
structure of the $\mathrm{Mg}\left(\mathrm{B}_{3} \mathrm{H}_{8}\right)_{2}(\mathrm{THF})_{2}$ molecule. We have found that $\mathrm{Mg}$ is directly linked to each octahydrotriborate ion by two $\mathrm{B}-\mathrm{Mg}$ and two bridge $\mathrm{B}-\mathrm{H}-\mathrm{Mg}$ bonds.

\section{MATERIALS AND METHODS}

$\mathrm{Mg}\left(\mathrm{B}_{3} \mathrm{H}_{8}\right)_{2}(\mathrm{THF})_{2}\left(\mathrm{THF}=\right.$ tetrahydrofuran) was prepared by the addition of $\mathrm{BH}_{3} \cdot \mathrm{THF}$ to $\mathrm{Mg} / \mathrm{Hg}$ amalgam, using the procedure reported in Ref. 6 .

In recent works about borohydrides, the $\mathrm{KBr}$ technique has been avoided because $\mathrm{BH}_{4}$ can exchange with $\mathrm{Br}$, due to their similar ionic radii.[14] In the present case, the radius of $\mathrm{B}_{3} \mathrm{H}_{8}$ is much larger and should not give this problem. However, in order to exclude spurious effects we performed infrared spectroscopy measurements in two different configurations: in transmission geometry using a pure pellet (without $\mathrm{KBr}$ or other salts) or by means of an Attenuated Total Reflectance accessory (ATR) on the hydride powders. The first method gives saturated bands in the $\mathrm{BH}$ stretching region, but provides very well defined spectra below $1700 \mathrm{~cm}^{-1}$, where the intensity of bands is much lower. On the other hand, the second method is well suited in the $\mathrm{BH}$ stretching region. It must be noted, however, that ATR displays the same features obtained in the case of the pure pellet below $1700 \mathrm{~cm}^{-1}$, but with a lower quality of the measurement. Therefore, in the following we will report data obtained by ATR between 1800 and $3300 \mathrm{~cm}^{-1}$ and by transmission measurements on the pure pellet in the frequency range $600-1700 \mathrm{~cm}^{-1}$. In this framework, infrared spectroscopy measurements below $1800 \mathrm{~cm}^{-1}$ were performed at room temperature by means of a Agilent Cary 660 spectrometer equipped with a ceramic source, a MCT detector and a $\mathrm{KBr}$ beamsplitter. A small amount of the sample was pressed in a dye in order to obtain a self standing pellet. As $\mathrm{Mg}\left(\mathrm{B}_{3} \mathrm{H}_{8}\right)_{2}(\mathrm{THF})_{2}$ is sensitive to air, the pellet was placed in a vacuum tight cell during measurements. Above $1800 \mathrm{~cm}^{-1}$ data were collected by means of a Bruker Alpha spectrometer equipped with an ATR 
accessory. In all cases, all handling of the sample was performed in a glove bag fluxed by an inert argon atmosphere to avoid contaminations $[15,16]$. All absorption spectra were collected with a spectral resolution of $2 \mathrm{~cm}^{-1}$.

\section{CALCULATION}

Preliminary geometries of the isolated $\left[\mathrm{B}_{3} \mathrm{H}_{8}\right]^{-}$, THF and $\mathrm{Mg}\left(\mathrm{B}_{3} \mathrm{H}_{8}\right)_{2}(\mathrm{THF})_{2}$ were obtained by means of the Avogadro software using the universal force field energy minimization routine. $[17,18] \mathrm{Ab}$-initio and DFT calculations were performed starting from those geometries by means of the Firefly package. $[19,20]$ In all cases we used the $6-31 G^{* *}$ basis set. The wxMacMolPIt software was used to visualize the molecular geometries and vibrations [21]. After calculation of the infrared active vibrations, the IR spectrum was simulated by summing Lorentzian curves centered at each calculated IR vibration frequency with a fixed $10 \mathrm{~cm}^{-1}$ peak width.

\section{RESULTS AND DISCUSSION}

\subsection{The isolated $\left[\mathrm{B}_{3} \mathrm{H}_{8}\right]^{-}$ion}

Preliminary ab-initio and DFT calculations were performed on isolated $\left[\mathrm{B}_{3} \mathrm{H}_{8}\right]^{-}$and THF, in order to verify that the geometries agree with those found experimentally: i.e. in THF the four $\mathrm{C}$ atoms reside in the same plane, whilst the $\mathrm{O}$ atom is located outside; for $\left[\mathrm{B}_{3} \mathrm{H}_{8}\right]^{-}$two $\mathrm{H}$ atoms reside in the plane of the three B atoms (see Fig. S1 of the Supplementing Material). In the present work we optimize geometries with the following theories: MP2, B3LYP and B97D. Table S1 reports the main bond lengths found in this study. One can note a good agreement with those reported in a previous DFT study $[12,13]$ and those 
found experimentally $[22,23]$.

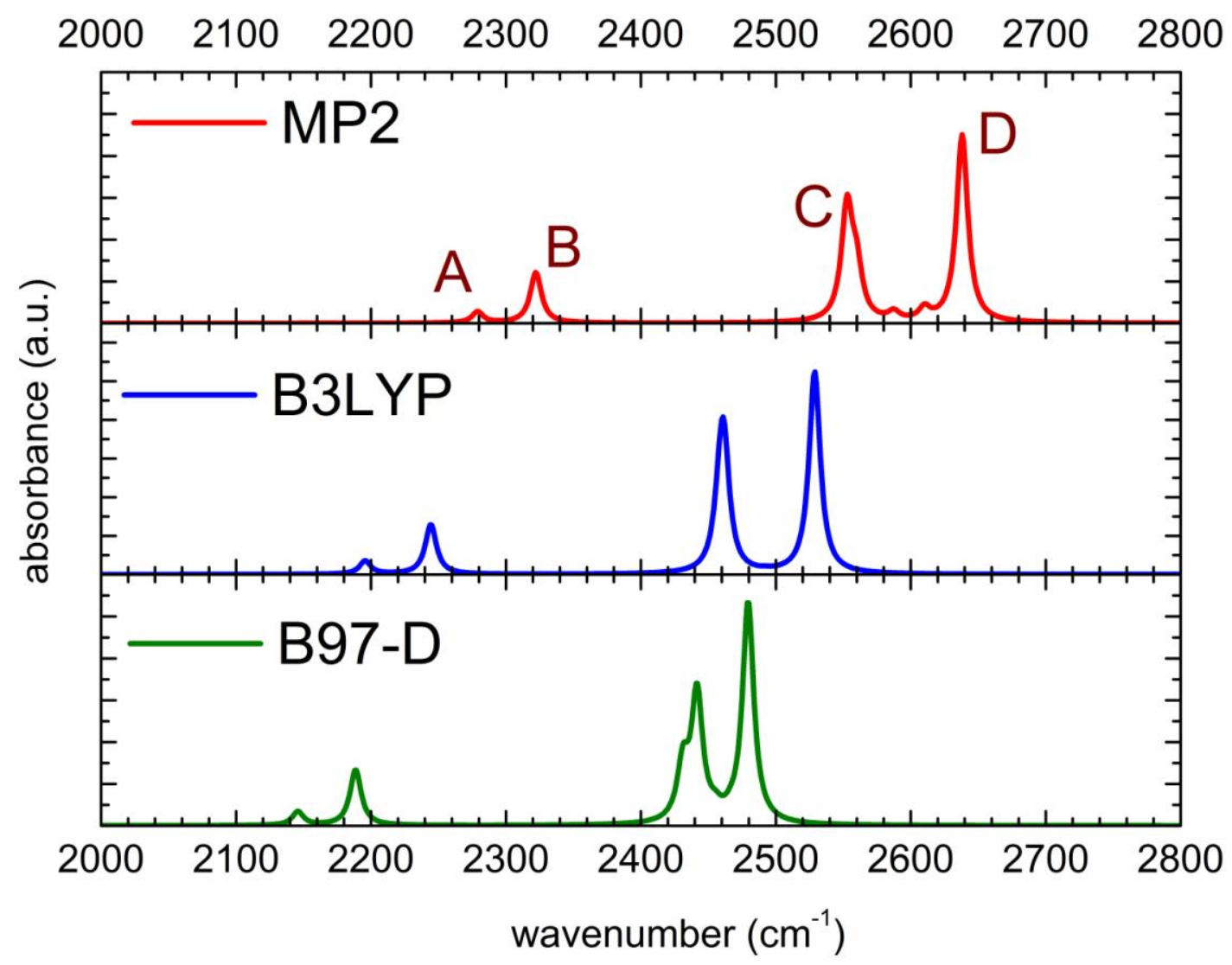

Fig. 1 Comparison of the calculated infrared absorption of isolated $\left[\mathrm{B}_{3} \mathrm{H}_{8}\right]^{-}$at the MP2, B3LYP and B97-D level of theories.

The infrared active vibrations of isolated $\left[\mathrm{B}_{3} \mathrm{H}_{8}\right]^{-}$were calculated with the various theories and the simulated absorbance curves are reported in Fig. 1. All the three used theories provide evidence that in the region of the $\mathrm{B}-\mathrm{H}$ stretching, one finds two less intense bands below $2400 \mathrm{~cm}^{-1}$ (band $A$ and $B$ ) which are due to bridging $\mathrm{B}-\mathrm{H}-\mathrm{B}$ movements and two structured bands $(C$ and $D)$ in the frequency region between 2450 and $2700 \mathrm{~cm}^{-1}$, which can be attributed to terminal B-H stretching. The spectra calculated by the different theories look similar, but are almost rigidly shifted toward lower frequency in the following order: MP2, B3LYP and B97D. All theories are able to give the main features of the 
infrared spectrum of isolated $\left[\mathrm{B}_{3} \mathrm{H}_{8}\right]^{-}$ion. It should be noted that in most samples [8] the experimental bands A and B are centered between 2050 and $2150 \mathrm{~cm}^{-1}$, whilst bands $C$ and $D$ are found between 2400 and $2600 \mathrm{~cm}^{-1}$. In Fig. 1 it seems that the frequencies calculated by the theory B97-D are in closer agreement with the experimental values. One must keep in mind, however, that experimental infrared spectra of molecules in which the octahydrotriborate ion is linked to an atom display additional bands in the frequency range between lines A-B and C-D.[8]

The IR active vibrations of isolated THF are above this spectral range. In fact, experimentally THF possesses intense IR bands around 2975, 2960, 2891, 1460, 1450 $\mathrm{cm}^{-1}$ and below.[24] Computationally those bands are shifted toward higher energies by about $100 \mathrm{~cm}^{-1}$.

\subsection{The $\mathrm{Mg}\left(\mathrm{B}_{3} \mathrm{H}_{8}\right)_{2}(\mathrm{THF})_{2}$ complex}

Fig. 2 displays the experimental absorption spectrum of $\mathrm{Mg}\left(\mathrm{B}_{3} \mathrm{H}_{8}\right)_{2}(\mathrm{THF})_{2}$ in the region of B-H stretching bands.

First of all, we did not observe $\mathrm{OH}$ stretching bands above $3000 \mathrm{~cm}^{-1}$, which would indicate contamination from water; the structured absorption band reported in Fig. 2 between 2800 and $3100 \mathrm{~cm}^{-1}$ is due to the vibrations of the THF molecules of $\mathrm{Mg}\left(\mathrm{B}_{3} \mathrm{H}_{8}\right)_{2}(\mathrm{THF})_{2}$. Moreover, previous NMR measurements [6] indicated that no other borohydride except $\mathrm{B}_{3} \mathrm{H}_{8}$ should be present. Both observations suggest the occurrence of a pure sample, without important contaminations.

In Fig. 2 one can note the presence of two weaker bands around 2069 and $2115 \mathrm{~cm}^{-1}$ and two strong bands around 2385 and $2432 \mathrm{~cm}^{-1}$. Moreover, a large and structured band around $2300 \mathrm{~cm}^{-1}$ is clearly visible. This band was attributed to the stretching vibrations of the B-H-Mg in similar compounds. [8] Therefore, our compound has a molecular structure 
with $\mathrm{Mg}$ directly linked to the octahydrotriborate ion. Very recently it has been shown that also the newly synthesized $\mathrm{LiB}_{3} \mathrm{H}_{8}(\mathrm{THF})$ complex shows infrared absorption bands due to Li-H-B bridging bonds.[25] However, computational work should be used to identify the most stable structure of $M g\left(B_{3} H_{8}\right)_{2}(T H F)_{2}$, i.e. whether $M g$ is linked to one, two or three $B$ atoms and how many $\mathrm{H}$ bridge bonds are present.

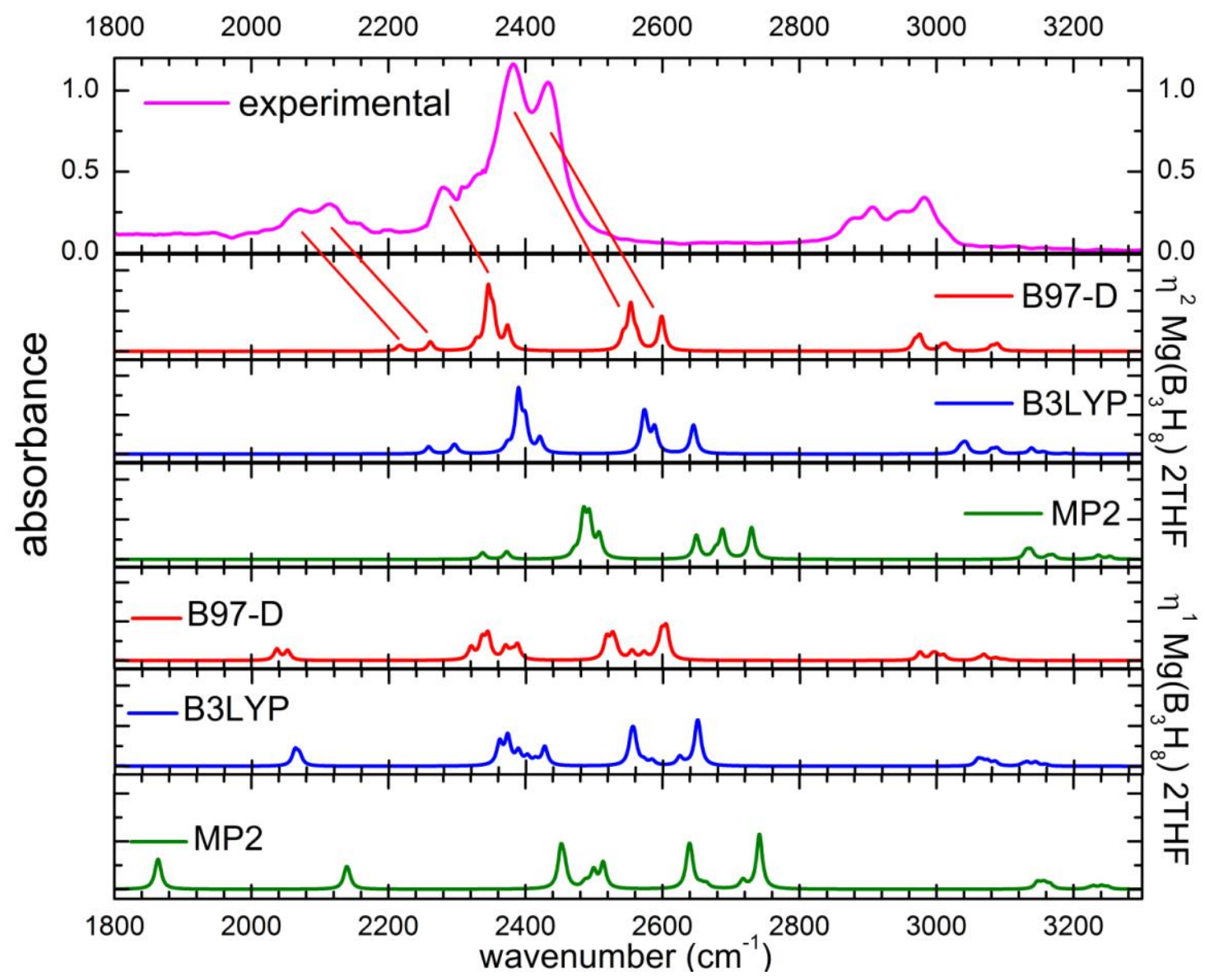

Fig. 2 Comparison of the measured infrared absorption with calculations for $\eta^{1}$ $\mathrm{Mg}\left(\mathrm{B}_{3} \mathrm{H}_{8}\right)_{2}(\mathrm{THF})_{2}$ and $\eta^{2}-\mathrm{Mg}\left(\mathrm{B}_{3} \mathrm{H}_{8}\right)_{2}(\mathrm{THF})_{2}$ at the MP2, B3LYP and B97-D level of theories.

We explored these various geometries for the $\mathrm{Mg}\left(\mathrm{B}_{3} \mathrm{H}_{8}\right)_{2}(\mathrm{THF})_{2}$ complex. Similar systems in which a metal atom was linked to the $\mathrm{B}_{3} \mathrm{H}_{8}$ ion and some other organic molecules, such 
as diethyl ether, methyl ether, cyclopentadienyl or THF were used as a starting point.[8,9] In the compounds containing THF, tetrahydrofuran is attached to the metal atom through the $\mathrm{O}$ atom.[8] Therefore, we started the optimizing procedure from a geometry with the two THF molecules pointing towards $\mathrm{Mg}$ by means of the $\mathrm{O}$ atom. $\mathrm{B}_{3} \mathrm{H}_{8}$ groups can be attached to Mg by means of one, two or three B-Mg chemical bonds $\left(\eta^{1}, \eta^{2}\right.$ and $\eta^{3}$ structures).[8, 9] We could not obtain any stable structure in which there are three boron atom for each $\mathrm{B}_{3} \mathrm{H}_{8}$ group linked to $\mathrm{Mg}$ atom. Indeed, during the attempted optimization procedure the octahydrotriborate broke up. Table 1 reports the energies of the optimized geometries of $\eta^{1}$ and $\eta^{2} \mathrm{Mg}\left(\mathrm{B}_{3} \mathrm{H}_{8}\right)_{2}(T H F)_{2}$ at the MP2, B97D and B3LYP level of theory, while Fig. 3 displays the optimized geometries at the MP2 level.

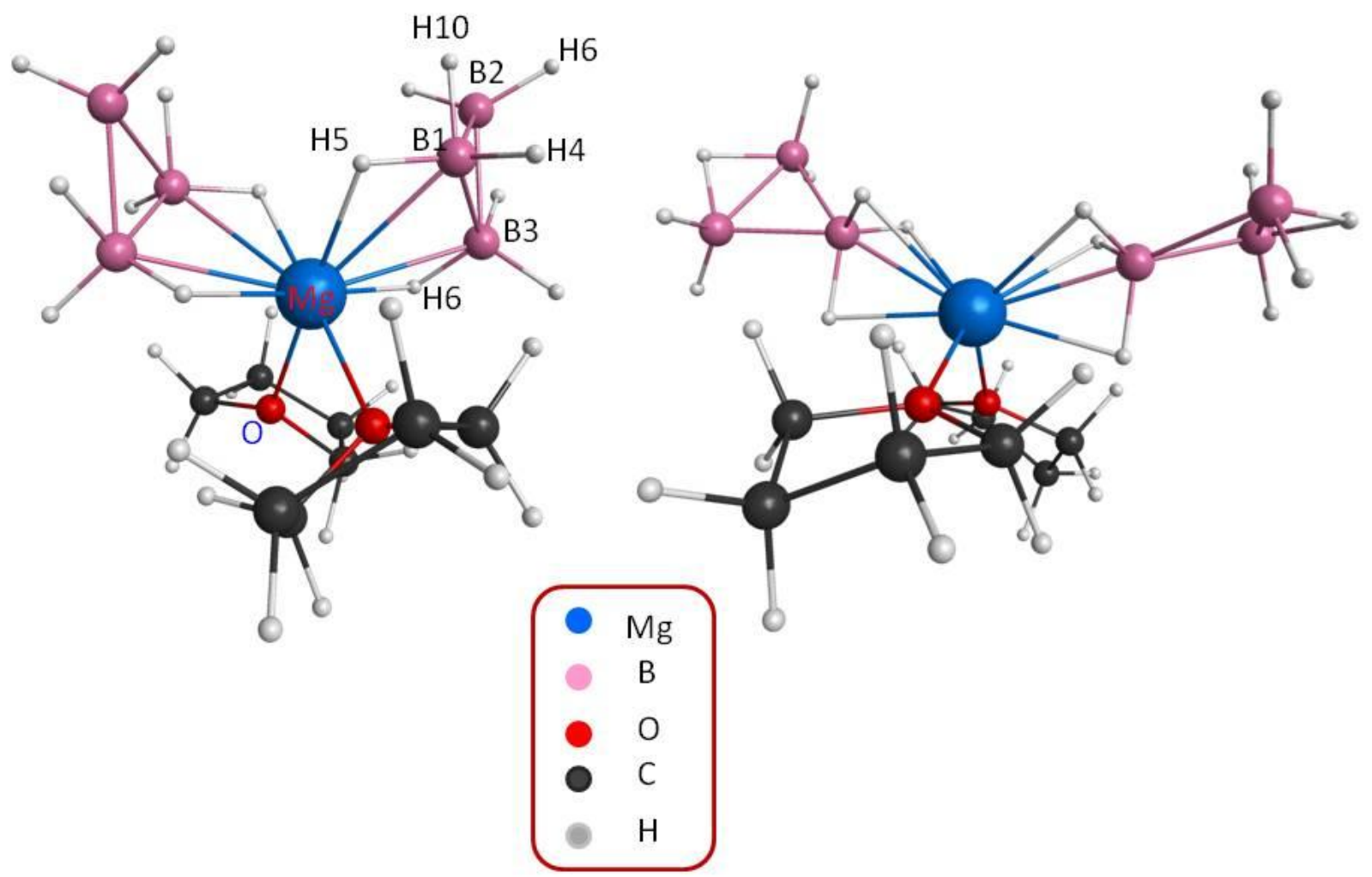


Fig. 3 Optimized geometries for $\eta^{1}-\mathrm{Mg}\left(\mathrm{B}_{3} \mathrm{H}_{8}\right)_{2}(\mathrm{THF})_{2}$ (on the right) and $\eta^{2}$ $\mathrm{Mg}\left(\mathrm{B}_{3} \mathrm{H}_{8}\right)_{2}(\mathrm{THF})_{2}$ (on the left) at the MP2 level.

The data presented in Table 1 shows that independently of the theory used for calculations, the $\eta^{2}$ structure has always a lower energy than the $\eta^{1}$ and, therefore, the former is the most thermodynamically stable. Table 2 reports the length of the main bonds found for $\mathrm{Mg}\left(\mathrm{B}_{3} \mathrm{H}_{8}\right)_{2}(\mathrm{THF})_{2}$ at the different levels of theory. The $\mathrm{B}-\mathrm{H}$ bond lengths are generally overestimated, but there is a general good agreement between calculated and experimental $\mathrm{B}-\mathrm{B}, \mathrm{Mg}-\mathrm{B}, \mathrm{Mg}-\mathrm{H}$ and $\mathrm{Mg}-\mathrm{O}$ bond lengths measured in similar systems.

Table 1 Energies of different optimized geometric structures of $M g\left(B_{3} H_{8}\right)_{2}(T H F)_{2}$ (in Hartree) at various theory levels. In all cases the basis set is fixed at the $6-31 G^{\star *}$ level.

\begin{tabular}{|l|l|l|}
\hline & \multicolumn{1}{|c|}{$\eta^{1}$} & \multicolumn{1}{|c|}{$\eta^{2}$} \\
\hline MP2 & -821.2082062 & -821.2220657 \\
\hline B97D & -823.3737212 & -823.3898445 \\
\hline B3LYP & -823.8287362 & -823.8345862 \\
\hline
\end{tabular}

Table 2 Main bond length of $\mathrm{Mg}\left(\mathrm{B}_{3} \mathrm{H}_{8}\right)_{2}(\mathrm{THF})_{2}$ at different levels of theory and comparison with the experimental values reported for $\mathrm{Mg}\left(\mathrm{B}_{3} \mathrm{H}_{8}\right)_{2}\left(\mathrm{Et}_{2} \mathrm{O}\right)_{2}, \mathrm{Mg}\left(\mathrm{B}_{3} \mathrm{H}_{8}\right)_{2}\left(\mathrm{Me}_{2} \mathrm{O}\right)_{2}$ and $\mathrm{Cp}_{2} \mathrm{Mg}(\mathrm{THF})$ obtained by means of XRD measurements [8].

\begin{tabular}{|l|l|l|l|l|l|l|}
\hline & $\begin{array}{l}\eta^{2} \\
\text { this study } \\
\text { MP2 }\end{array}$ & $\begin{array}{l}\eta^{2} \\
\text { this study } \\
\text { B3LYP }\end{array}$ & $\begin{array}{l}\eta^{2} \\
\text { this study } \\
\text { B97D }\end{array}$ & $\begin{array}{l}\text { Exp } \\
\mathrm{Mg}\left(\mathrm{B}_{3} \mathrm{H}_{8}\right)_{2} \\
\left(\mathrm{Et}_{2} \mathrm{O}\right)_{2} \\
{[8]}\end{array}$ & $\begin{array}{l}\text { Exp } \\
\mathrm{Mg}\left(\mathrm{B}_{3} \mathrm{H}_{8}\right)_{2} \\
\left(\mathrm{Me}_{2} \mathrm{O}\right)_{2} \\
{[8]}\end{array}$ & $\begin{array}{l}\text { Exp } \\
\mathrm{Cp}_{2} \mathrm{Mg}(\mathrm{THF}) \\
{[8]}\end{array}$ \\
\hline $\mathrm{B} 1-\mathrm{H} 4$ & $1.19-1.22$ & 1.20 & 1.21 & $1.12-1.17$ & $1.08-1.14$ & \\
\hline
\end{tabular}




\begin{tabular}{|l|l|l|l|l|l|l|}
\hline B1-H10 & $1.24-1.25$ & $1.25-1.26$ & $1.26-1.27$ & 1.02 & $1.10-1.17$ & \\
\hline B2-H10 & $1.41-1.44$ & $1.42-1.45$ & $1.45-1.49$ & 1.43 & $1.38-1.45$ & \\
\hline B2-H6 & 1.19 & 1.20 & 1.21 & 1.02 & $1.11-1.17$ & \\
\hline B1-B2 & 1.81 & $1.81-1.82$ & $1.81-1.82$ & 1.795 & $1.780-1.803$ & \\
\hline B1-B3 & 1.79 & 1.79 & 1.81 & 1.779 & $1.777-1.795$ & \\
\hline B3-Mg & 2.51 & 2.52 & 2.58 & 2.575 & 2.559 & \\
\hline B1-Mg & 2.54 & 2.55 & 2.62 & 2.591 & 2.572 & \\
\hline H5-Mg & 1.95 & 1.97 & 1.96 & 1.99 & 1.91 & \\
\hline H6-Mg & 1.97 & 1.99 & 1.99 & 2.01 & 1.98 & \\
\hline Mg-O & 2.10 & 2.12 & 2.10 & & & 2.093 \\
\hline H5-B1 & 1.22 & $1.22-1.23$ & $1.23-1.24$ & 1.17 & $1.14-1.19$ & \\
\hline
\end{tabular}

To confirm that the compound has an $\eta^{2}$ structure, we calculated the infrared absorption spectrum of both $\eta^{1}-\mathrm{Mg}\left(\mathrm{B}_{3} \mathrm{H}_{8}\right)_{2}(\mathrm{THF})_{2}$ and $\eta^{2}-\mathrm{Mg}\left(\mathrm{B}_{3} \mathrm{H}_{8}\right)_{2}(\mathrm{THF})_{2}$ at the three theory levels (MP2, B3LYP and B97-D). The calculated absorptions are seen in Figure 2. The spectra obtained by means of different theories for each structure are very similar, except that they are shifted toward higher frequencies as one proceeds from B97-D, to B3LYP and finally to MP2. For the $\eta^{1}$ structure the frequencies of the bridged B-H-B vibrations are usually underestimated; moreover, for B3LYP and MP2 the B-H-B stretching frequencies are so close that they could not be resolved and would appear as a single band in an infrared spectrum. Generally, for each level of computation, the calculated absorbance of the $\eta^{2}$ structure is much less structured than that of the $\eta^{1}$ structure and more closely resembles the experimental absorption spectrum. These features and the results of the minimization of energy suggest that the actual structure of $\mathrm{Mg}\left(\mathrm{B}_{3} \mathrm{H}_{8}\right)_{2}(\mathrm{THF})_{2}$ is the $\eta^{2}$. 
Table 3 displays the infrared active stretching vibrations frequencies found at the MP2, B3LYP and B97-D level for $\eta^{2}-\mathrm{Mg}\left(\mathrm{B}_{3} \mathrm{H}_{8}\right)_{2}(T H F)_{2}$. The vibration frequencies calculated at the B97-D level of theory are the closer to the experimental ones. However, it can be noted, that despite the succession of infrared lines is correctly described by calculations, all experimental frequencies are lower than those calculated by all models. Possibly this fact can be due to the anharmonicity of the B-H bonds, similarly to the case of alkali borohydrides containing $\mathrm{BH}_{4}$ ions.[26]

Table 3 Calculated infrared vibration frequencies and intensities of $\eta^{2}-M g\left(B_{3} H_{8}\right)_{2}(T H F)_{2}$ at different level of theory in the region of the $\mathrm{B}-\mathrm{H}$ stretching vibrations and comparison with the frequencies of the experimental bands.

\begin{tabular}{|c|c|c|c|c|c|c|c|}
\hline \multirow[t]{2}{*}{ attribution } & \multicolumn{2}{|c|}{ MP2 } & \multicolumn{2}{|c|}{ B3LYP } & \multicolumn{2}{|c|}{ B97D } & \multirow{2}{*}{$\begin{array}{c}\text { Exp } \\
\omega\left(\mathrm{cm}^{-1}\right)\end{array}$} \\
\hline & $\omega\left(\mathrm{cm}^{-1}\right)$ & $\begin{array}{c}\mathrm{I} \\
(\mathrm{km} / \mathrm{mol})\end{array}$ & $\omega\left(\mathrm{cm}^{-1}\right)$ & $\begin{array}{c}\mathrm{I} \\
(\mathrm{km} / \mathrm{mol})\end{array}$ & $\omega\left(\mathrm{cm}^{-1}\right)$ & $\begin{array}{c}\mathrm{I} \\
(\mathrm{km} / \mathrm{mol})\end{array}$ & \\
\hline \multirow{4}{*}{$\begin{array}{l}\text { Bridged } \\
\text { B-H-B } \\
\text { stretching }\end{array}$} & 2336 & 31.4 & 2259 & 21.1 & 2214 & 23.3 & 2069 \\
\hline & 2337 & 23.7 & 2259 & 40.2 & 2217 & 28.9 & 2115 \\
\hline & 2372 & 37.7 & 2295 & 43.8 & 2260 & 39.3 & \\
\hline & 2372 & 25.5 & 2298 & 42.7 & 2260 & 35.3 & \\
\hline \multirow{4}{*}{$\begin{array}{l}\text { Bridged } \\
\text { Mg-H-B } \\
\text { stretching }\end{array}$} & 2470 & 48.2 & 2374 & 59.2 & 2327 & 64.2 & 2280 \\
\hline & 2484 & 343.4 & 2390 & 505.2 & 2344 & 460.5 & 2325 \\
\hline & 2492 & 307.5 & 2400 & 249.5 & 2352 & 251.0 & \\
\hline & 2507 & 181.0 & 2421 & 123.8 & 2373 & 187.9 & \\
\hline \multirow{2}{*}{ Terminal } & 2648 & 125.1 & 2572 & 145.6 & 2542 & 58.8 & 2383 \\
\hline & 2649 & 71.7 & 2574 & 142.9 & 2542 & 45.9 & 2432 \\
\hline
\end{tabular}




\begin{tabular}{|r|r|r|r|r|r|r|r|}
\hline \multirow{2}{*}{ B-H } & 2676 & 28.9 & 2576 & 41.0 & 2552 & 237.2 & \\
\cline { 2 - 8 } & 2677 & 30.5 & 2577 & 62.8 & 2553 & 125.4 & \\
\cline { 2 - 8 } & 2686 & 215.0 & 2588 & 179.4 & 2561 & 44.4 & \\
& 2689 & 23.1 & 2591 & 28.0 & 2562 & 53.7 & \\
\hline & 2729 & 240.8 & 2645 & 161.9 & 2597 & 180.4 & \\
\hline & 2730 & 22.0 & 2647 & 91.2 & 2599 & 112.8 & \\
\hline
\end{tabular}

Finally Figure 4 displays the typical movements occurring in the three types of stretching vibrations: bridged $\mathrm{B}-\mathrm{H}-\mathrm{B}$, bridged $\mathrm{Mg}-\mathrm{H}-\mathrm{B}$ and terminal $\mathrm{B}-\mathrm{H}$.

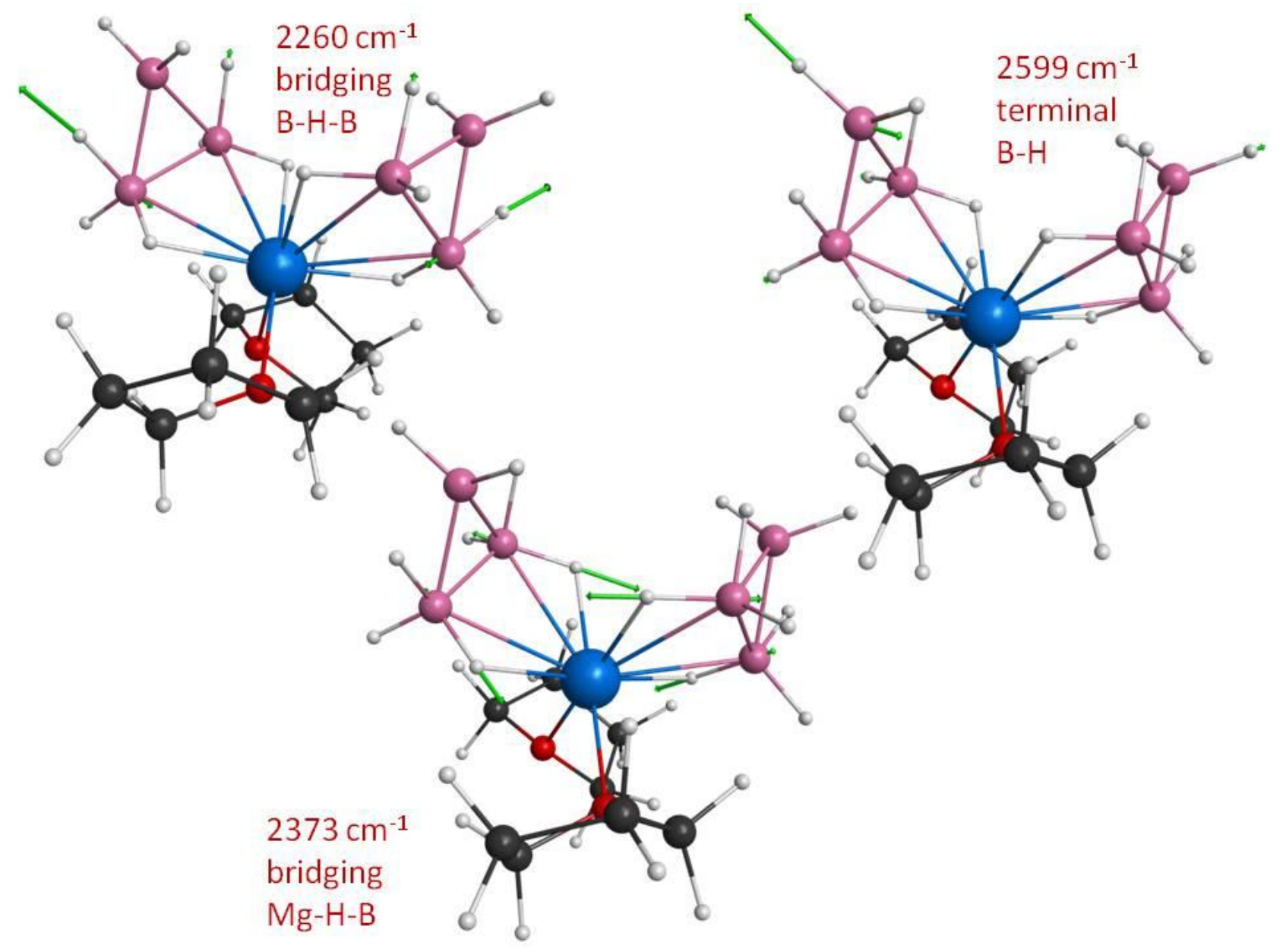


Fig. 4 Atomic displacements corresponding to selected vibrations calculated at the B97-D level, representing $\mathrm{B}-\mathrm{H}-\mathrm{B}$ bridging, $\mathrm{Mg}-\mathrm{H}-\mathrm{B}$ bridging and terminal $\mathrm{B}-\mathrm{H}$ stretching movements.

The investigation of the infrared spectrum of the $\mathrm{Mg}\left(\mathrm{B}_{3} \mathrm{H}_{8}\right)_{2}(\mathrm{THF})_{2}$ compound was extended to lower frequencies. Fig. 5 reports the experimental absorption spectrum between 600 and $1700 \mathrm{~cm}^{-1}$. Well defined peaks are visible around $678,707,846,868$, 922, 966, 1010, 1040, 1138, 1180, 1250, 1297, 1315, 1348, $1456 \mathrm{~cm}^{-1}$, while a broad band extends up to $\sim 1600 \mathrm{~cm}^{-1}$. We did not observe the band centered around $1630 \mathrm{~cm}^{-1}$, due to possible water contamination. There is a general good agreement of the calculated and experimental bands below $1200 \mathrm{~cm}^{-1}$. Above this frequency the experimental spectrum becomes less well defined and a comparison with calculations is more difficult, possibly because of the amorphous nature of the compound, which broadens the absorption bands. This behavior is different from that of other hydrides, like for example $\mathrm{NH}_{3} \mathrm{BH}_{3}$, which due to their crystalline structure display very well defined absorption bands in the whole infrared range.[27] 


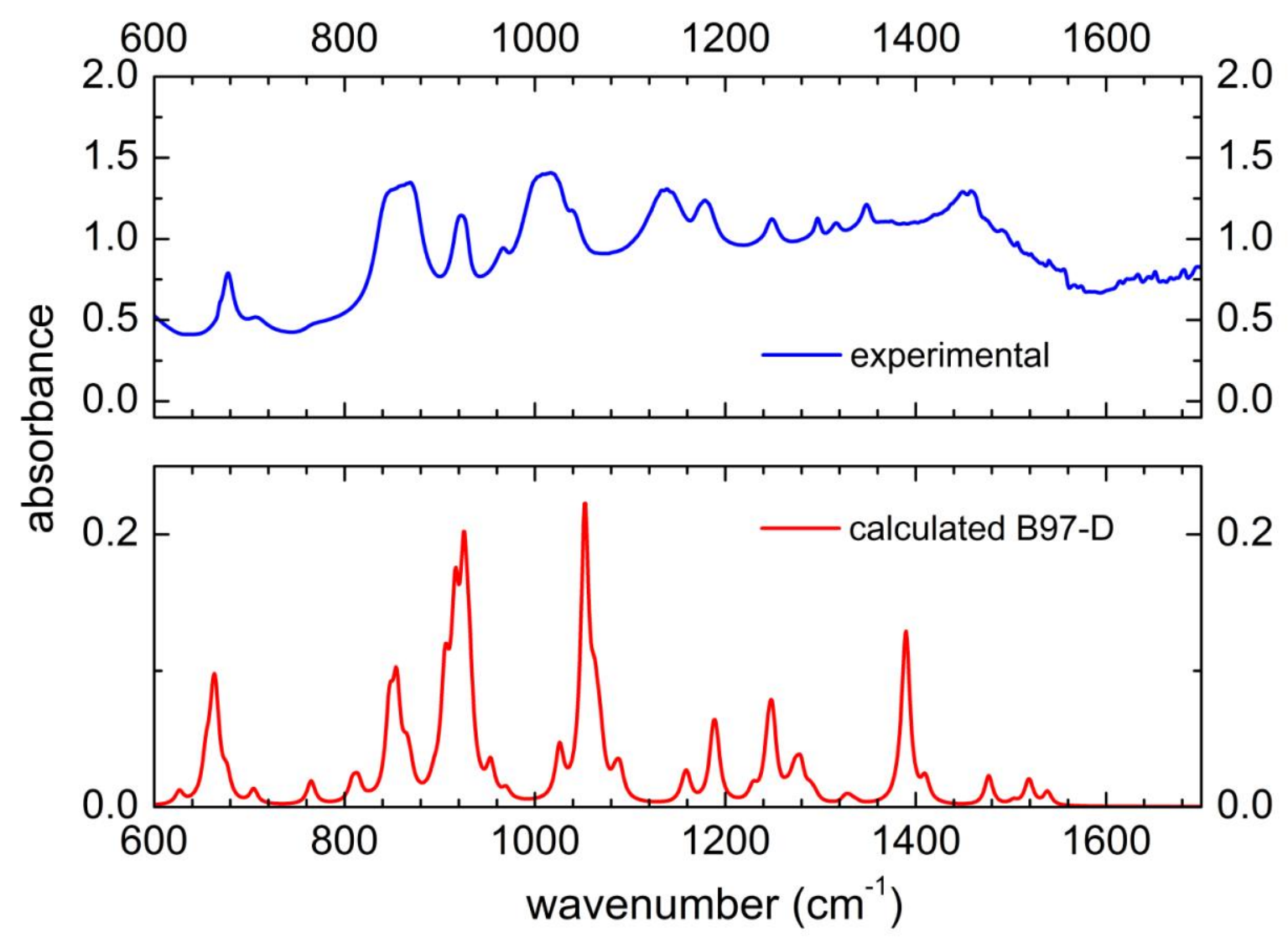

Fig. 5 Comparison of the experimental and calculated absorption spectrum of $\mathrm{Mg}\left(\mathrm{B}_{3} \mathrm{H}_{8}\right)_{2}(\mathrm{THF})_{2}$, in the frequency range between 600 and $1700 \mathrm{~cm}^{-1}$.

Once the structure of the new $\mathrm{Mg}\left(\mathrm{B}_{3} \mathrm{H}_{8}\right)_{2}(\mathrm{THF})_{2}$ compound is proposed thanks to the previous combined computational/experimental work, one can investigate the formation energy of the complex, also in comparison with $\mathrm{Mg}\left(\mathrm{B}_{3} \mathrm{H}_{8}\right)_{2}\left(\mathrm{Et}_{2} \mathrm{O}\right)_{2}$ and $\mathrm{Mg}\left(\mathrm{B}_{3} \mathrm{H}_{8}\right)_{2}\left(\mathrm{Me}_{2} \mathrm{O}\right)_{2}$. We calculated the formation energy of $\mathrm{Mg}\left(\mathrm{B}_{3} \mathrm{H}_{8}\right)_{2} \mathrm{M}_{2}$ as:

$E_{\text {form }}=E\left(M g\left(B_{3} H_{8}\right)_{2} S_{2}\right)-E\left(M g\left(B_{3} H_{8}\right)_{2}\right)-2 E(S)$

where $\mathrm{S}=\mathrm{THF}, \mathrm{Me}_{2} \mathrm{O}$ or $\mathrm{Et}_{2} \mathrm{O}$. Magnesium octahydrotriborate has been recently reported to be an amorphous solid.[28] However, a detailed structural investigation is not available. We minimized the energy of an hypothetical $\mathrm{Mg}\left(\mathrm{B}_{3} \mathrm{H}_{8}\right)_{2}$ molecule, starting from the $\mathrm{Mg}\left(\mathrm{B}_{3} \mathrm{H}_{8}\right)_{2}(\mathrm{THF})_{2}$ compound and removing THF. For this purpose we adopted ab-initio 
calculations at the MP2 level of theory. The stable structure of magnesium octahydrotriborate, reported in Fig. 6 , shows that each $\mathrm{B}_{3} \mathrm{H}_{8}$ ion is linked to $\mathrm{Mg}$ by three $\mathrm{B}$ $\mathrm{Mg}$ and three $\mathrm{B}-\mathrm{H}-\mathrm{Mg}$ bonds. Conversely both $\mathrm{Mg}\left(\mathrm{B}_{3} \mathrm{H}_{8}\right)_{2}\left(\mathrm{Et}_{2} \mathrm{O}\right)_{2}$ and $\mathrm{Mg}\left(\mathrm{B}_{3} \mathrm{H}_{8}\right)_{2}\left(\mathrm{Me}_{2} \mathrm{O}\right)_{2}$ show an $\eta^{2}$ structure (see Fig. 6), similar to that here proposed for $M g\left(B_{3} H_{8}\right)_{2}(T H F)_{2}$, in agreement with the structure proposed by Kim et al. [8] on the basis of diffraction studies.
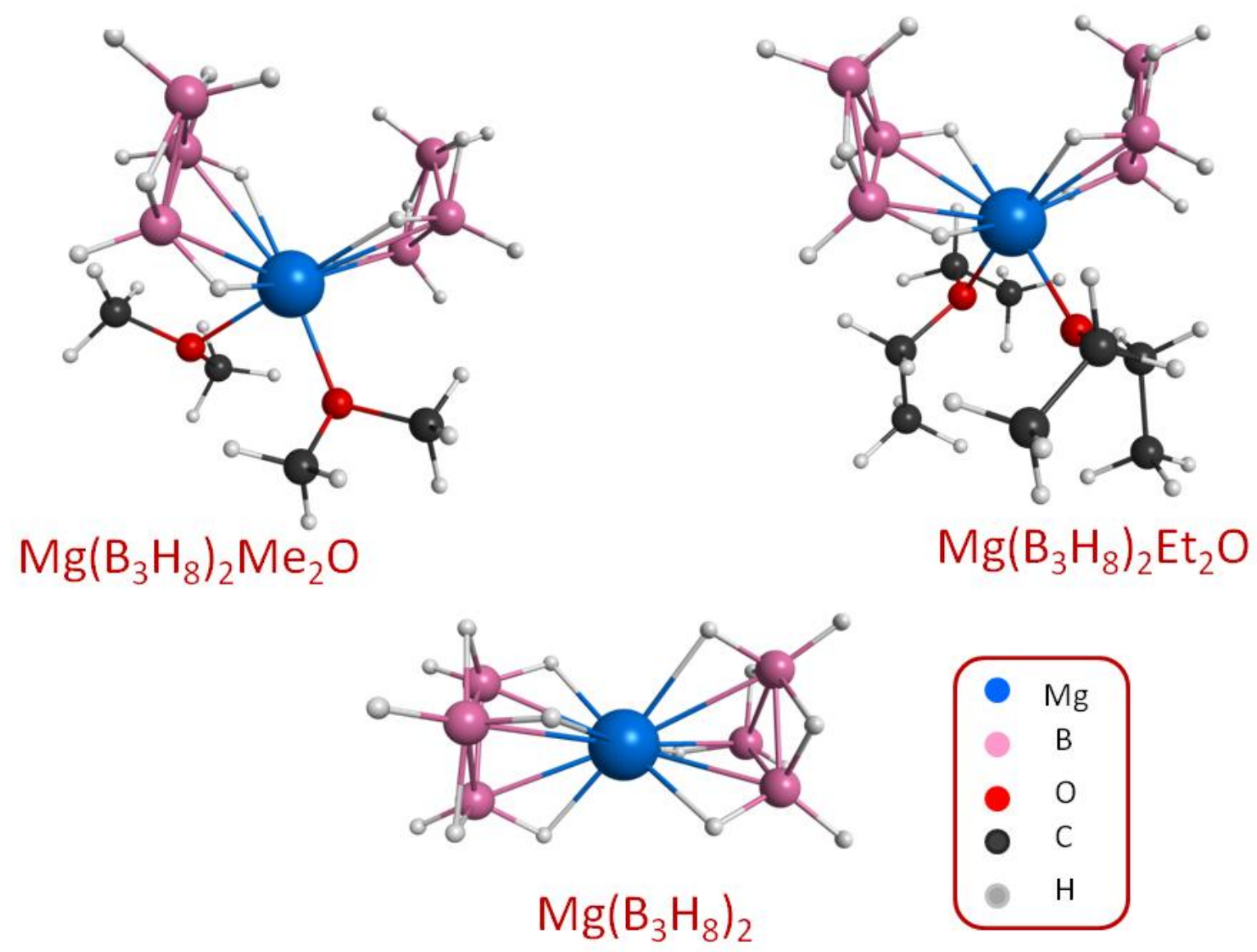

Fig. 6 Optimized geometries of $\mathrm{Mg}\left(\mathrm{B}_{3} \mathrm{H}_{8}\right)_{2}, \mathrm{Mg}\left(\mathrm{B}_{3} \mathrm{H}_{8}\right)_{2}\left(\mathrm{Me}_{2} \mathrm{O}\right)_{2}$ and $\mathrm{Mg}\left(\mathrm{B}_{3} \mathrm{H}_{8}\right)_{2}\left(\mathrm{Et}_{2} \mathrm{O}\right)_{2}$ at the MP2 level.

Table 4 reports the calculated energies of $\mathrm{Mg}\left(\mathrm{B}_{3} \mathrm{H}_{8}\right)_{2}, \mathrm{THF}, \mathrm{Me}_{2} \mathrm{O}, \mathrm{Et}_{2} \mathrm{O}$ and of the three complexes $\mathrm{Mg}\left(\mathrm{B}_{3} \mathrm{H}_{8}\right)_{2} \mathrm{~S}_{2}, \mathrm{~S}=\mathrm{THF}, \mathrm{Me}_{2} \mathrm{O}$ or $\mathrm{Et}_{2} \mathrm{O}$. From these values, one obtains that the 
formation energies of the two ether complexes are quite similar (-199 and $-203 \mathrm{~kJ} / \mathrm{mol}$ for $\mathrm{Me}_{2} \mathrm{O}$ and $\mathrm{Et}_{2} \mathrm{O}$ ), while $-227 \mathrm{~kJ} / \mathrm{mol}$ is calculated for $\mathrm{Mg}\left(\mathrm{B}_{3} \mathrm{H}_{8}\right)_{2}(\mathrm{THF})_{2}$. THF is, therefore, the molecule more strongly bound to magnesium octahydrotriborate.

Table 4. Calculated energies of molecules or complexes at the MP2 level. All values are expressed in Hartree.

\begin{tabular}{|l|l|}
\hline Molecule/complex & Energy (Hartree) \\
\hline THF & -231.7338875 \\
\hline Me2O & -154.5518258 \\
\hline Et2O & -232.9264952 \\
\hline $\mathrm{Mg}\left(\mathrm{B}_{3} \mathrm{H}_{8}\right)_{2}$ & -357.6679207 \\
\hline $\mathrm{Mg}\left(\mathrm{B}_{3} \mathrm{H}_{8}\right)_{2}(\mathrm{THF})_{2}$ & -821.2220657 \\
\hline $\mathrm{Mg}\left(\mathrm{B}_{3} \mathrm{H}_{8}\right)_{2}\left(\mathrm{Me}_{2} \mathrm{O}\right)_{2}$ & -666.8475019 \\
\hline $\mathrm{Mg}\left(\mathrm{B}_{3} \mathrm{H}_{8}\right)_{2}\left(\mathrm{Et}_{2} \mathrm{O}\right)_{2}$ & -823.5982098 \\
\hline
\end{tabular}

\section{CONCLUSIONS}

The combination of infrared spectroscopy, ab-initio (MP2) and DFT (B3LYP, B97-D) calculations have proven to be applicable methods for determination of the molecular structure of amorphous $\mathrm{Mg}\left(\mathrm{B}_{3} \mathrm{H}_{8}\right)_{2}(\mathrm{THF})_{2}$. We have found that $\mathrm{Mg}$ is directly linked to each octahydrotriborate ion by means of two B-Mg and two bridge B-H-Mg bonds. B97-D functional seems to be the best choice to reproduce the experimental spectrum in the whole mid infrared range between 600 and $3300 \mathrm{~cm}^{-1}$, even though anharmonicity of the $\mathrm{BH}$ stretching vibrations should be present. Moreover, calculations provide evidence of the 
stabilization of the THF solvate of $\mathrm{Mg}\left(\mathrm{B}_{3} \mathrm{H}_{8}\right)_{2}$ and indicate that the THF complex has greater stabilization energy that the dialkyl ethers complexes by $\sim 25 \mathrm{~kJ} / \mathrm{mol}$.

\section{ACKNOWLEDGEMENTS}

PN and CJ acknowledge the support of the US Department of Energy, Office of Energy Efficiency and Renewable Energy. 


\section{REFERENCES}

[1] Li HW, Yan Y, Orimo SI, Züttel A, Jensen CM. Recent progress in metal borohydrides for hydrogen storage. Energies 2011; 4: 185-214.

[2] Yan Y, Au YS, Rentsch D, Remhof A, de Jongh PE, Züttel A. Reversible hydrogen storage in $\mathrm{Mg}\left(\mathrm{BH}_{4}\right)_{2} /$ carbon nanocomposites. J Mater Chem A 2013; 1: 11177-11183.

[3] Li HW, Kikuchi K, Nakamori Y, Ohba N, Miwa K, Towata S, Orimo S. Dehydriding and rehydriding processes of well-crystallized $\mathrm{Mg}(\mathrm{BH} 4) 2$ accompanying formation of intermediate compounds. Acta Mater 2008; 56: 1342-1347.

[4] Severa G, Rönnebro E, Jensen CM. Direct hydrogenation of magnesium boride to magnesium borohydride: demonstration of $>11$ weight percent reversible hydrogen storage. Chem Comm 2010; 46: 421-423.

[5] Chong M, Karkamkar A, Autrey T, Orimo S, Jalisatgi S, Jensen CM. Reversible dehydrogenation of magnesium borohydride to magnesium triborane in the solid state under moderate conditions. Chem Comm 2011; 47: 1330-1332.

[6] Chong M, Matsuo M, Orimo SI, Autrey T, Jensen CM. Selective Reversible Hydrogenation of $\mathrm{Mg}\left(\mathrm{B}_{3} \mathrm{H}_{8}\right)_{2} / \mathrm{MgH}_{2}$ to $\mathrm{Mg}\left(\mathrm{BH}_{4}\right)_{2}$ : Pathway to Reversible Borane-Based Hydrogen Storage? Inorg Chem 2015; 54: 4120-4125.

[7] Nakamoto K. Infrared and Raman spectra of inorganic and coordination compounds, Part A: theory and applications in inorganic chemistry. 5th ed. New York: J. Wiley and Sons Inc.; 1997. 
[8] Kim DY, Yang Y, Abelson JR, Girolami GS. Volatile magnesium octahydrotriborate complexes as potential CVD precursors to $\mathrm{MgB}_{2}$. Synthesis and characterization of $\mathrm{Mg}\left(\mathrm{B}_{3} \mathrm{H}_{8}\right)_{2}$ and its etherates. Inorg Chem 2007; 46: 9060-9066.

[9] Bykov AY, Zhizhin KY, Kuznetsov NT. The chemistry of the octahydrotriborate anion $\left[\mathrm{B}_{3} \mathrm{H}_{8}\right]^{-}$. Russian Journal of Inorganic Chemistry 2014; 59: 1539-1555.

[10] Dunbar AC, Macor JA, Girolami GS. Synthesis and Single Crystal Structure of Sodium Octahydrotriborate, $\mathrm{NaB}_{3} \mathrm{H}_{8}$. Inorg Chem 2014; 53: 822-826.

[11] Hildebrandt SJ, Gaines DF, Calabrese JC. Low-temperature crystal and molecular structure of tricarbonyl[octahydrotriborato(1-)]manganese, $(\mathrm{CO})_{3} \mathrm{MnB}_{3} \mathrm{H}_{8}$. Inorg Chem 1978; 17: 790-794.

[12] Serrar C, Es-sofi A, Boutalib A, Ouassas A, Jarid A. Theoretical study of the structural and fluxional behavior of copper(I)-octahydrotriborate complex. J Phys Chem A 2001; 105: 9778-9780.

[13] Serrar C, Es-sofi A, Boutalib A, Ouassas A, Jarid A. Synthesis, structural characterization, and theoretical calculations of a new copper(I)-octahydrotriborate complex. Inorg Chem 2000; 39: 2224-2226.

[14] Palumbo O, Cantelli R, Paolone A, Jensen CM, Srinivasan SS. Point defect dynamics and evolution of chemical reactions in alanates by anelastic spectroscopy. J Phys Chem B 2005; 109: 1168-1173.

[15] Paolone A, Vico F, Teocoli F, Sanna S, Palumbo O, Cantelli R, Knight DA, Teprovich JA Jr, Zidan R. Relaxation processes and structural changes in Li- and Na-doped fulleranes for hydrogen storage. J Phys Chem C 2012; 116: 16365-16370. 
[16] Fichtner M, Chlopek K, Longhini M, Hagemann $\mathrm{H}$, Vibrational spectra of $\mathrm{Ca}\left(\mathrm{BH}_{4}\right)_{2 .} \mathrm{J}$ Phys Chem C 2008; 112: 11575-11579.

[17] Avogadro: an open-source molecular builder and visualization tool. Version 1.1.0, http://avogadro.openmolecules.net/

[18] Hanwell MD, Curtis DE, Lonie DC, Vandermeersch T, Zurek E, Hutchison GR. Avogadro: an advanced semantic chemical editor, visualization, and analysis platform. Journal of Cheminformatics 2012; 4: 17.

[19] Granovsky AA. Firefly version 8.0, http://classic.chem.msu.su/gran/firefly/index.html. [20] Schmidt MW, Baldridge KK, Boatz JA, Elbert ST, Gordon MS, Jensen JH, Koseki S, Matsunaga N, Nguyen KA, Su S, Windus TL, Dupuis M, Montgomery JAJ. General atomic and molecular electronic structure system. Comput Chem 1993; 14: 1347-1363.

[21] Bode BM, Gordon MS. A graphical user interface for GAMESS, J. Mol. Graph. Modell. 1998; 16: 133-138.

[22] Guggenberger LJ. The crystal structure of the tetramethylammonium salt of the octahydrotriborotetracarbonylchromium anion, $(\mathrm{CO})_{4} \mathrm{CrB}_{3} \mathrm{H}_{8}{ }^{-}$. Inorg Chem 1970; 368-373.

[23] Mitchell GF, Welch Al. Extended Hückel molecular orbital study of the effects of edgebridging hydrogen atoms on the lengths of boron-boron and metal-metal bonds in cluster compounds, and the crystal structure of benzyltrimethylammonium octahydrotriborate(1-). J Chem Soc Dalton Trans 1987; 1017-1025.

[24] Shurvell HF, Southby MC. Infrared and Raman spectra of tetrahydrofuran hydroperoxide. Vib Spec 1997; 15: 137-146. 
[25] Fu H, Wang X, Shao Y, Chen J, Zhang X, Fu H, Zheng J, Li X. Synthesis of lithium octahydrotriborate and investigation of its thermal decomposition. Int J Hydr Energy 2016; 41: 384-391.

[26] Carbonnière P, Hagemann H. Fermi resonances of borohydrides in a crystalline environment of alkali metals. J Phys Chem A 2006; 110: 9927-9933.

[27] Paolone A, Teocoli F, Sanna S, Palumbo, Autrey T. Temperature dependence of the infrared spectrum of ammonia borane: librations, rotations and molecular vibrations. $J$ Phys Chem C 2013; 117: 729-734.

[28] Huang J, Yan Y, Remhof A, Zhang Y, Rentsch D, Au YS, de Jongh PE, Cuevas F, Ouyang L, Zhu M, Züttel A. A novel method for the synthesis of solvent-free $\mathrm{Mg}\left(\mathrm{B}_{3} \mathrm{H}_{8}\right)_{2}$. Dalton Trans DOI: 10.1039/C5DT04517G. 